\title{
Adult Standardized Concentration of Cardiovascular Medications Intravenous infusion: A New Initiative in Saudi Arabia
}

\begin{abstract}
Yousef Ahmed Alomi* iD, BSC. Pharm, MSc. Clin Pharm, BCPS, BCNSP, DiBA, $\mathrm{CDE}$, Critical Care Clinical Pharmacists, TPN Clinical Pharmacist, Freelancer Business Planner, Content Editor and Data Analyst, Riyadh, Saudi Arabia.
\end{abstract}

Afnan Owedah Alshomrani, Pharm D, Pharmaceutical Care Department King Abdul-Aziz Medical, City-WR-Jeddah, Ministry of National Guard, Saudi Arabia.

Faiz Abdullah. Bahadig, R.Ph Informatics Pharmacist, Pharmaceutical Care Department, King Abdul-Aziz Medical, City-WR-Jeddah, Ministry of National Guard, Saudi Arabia.

Hani Alhamdan, BSc.Pharm, MSc. Pharm, MBA, Director, Pharmaceutical Care services Department at KAMC-Jeddah, Ministry of National Guard, Saudi Arabia.

\section{Correspondence:}

Dr. Yousef Ahmed Alomi, Bsc. Pharm, msc. Clin pharm, bcps, bCNSP, DiBA, CDE Critical Care Clinical Pharmacists, TPN Clinical Pharmacist, Freelancer Business Planner, Content Editor and Data Analyst, P.O.BOX 100, Riyadh 11392, Riyadh, SAUDI ARABIA.

Phone no: +966504417712

E-mail:yalomi@gmail.com

\section{Received: 17-10-2019;}

Accepted: 01-12-2019

Copyright: @ the author(s), publisher and licensee International Journal of Pharmacology and Clinical Sciences. This is an open-access article distributed under the terms of the Creative Commons Attribution Non-Commercial License, which permits unrestricted non-commercial use, distribution, and reproduction in any medium, provided the original work is properly cited.

This is an open access article distributed under the terms of the Creative Commons AttributionNonCommercial-ShareAlike 4.0 License

Access this article online

\begin{tabular}{|l|l|}
\hline & www.ijpcs.net \\
\hline & DOI: \\
\hline
\end{tabular}

\begin{abstract}
Objectives: To declare the adult standardized concentration of cardiovascular intravenous infusion as a new initiative in the Kingdom of Saudi Arabia. Methods: It is a new initiative project drove by national standardized concentration of cardiovascular services. The projects formulated from the international business model, pharmacy project guidelines and project management institution guidelines of a new project. The initiative project is written through project management professionals and consisted of several parts, including the initial phase, the planning phase, the execution phase, the monitoring and controlling phase. Results: The adult standardized concentration of cardiovascular medications intravenous infusion services defined as vision, mission and goals. The services had various benefits including clinical and economic on patients, the continuous of the project assured by risk management model description and the monitoring and controlling of the services as illustrated in the review. The transition to operation project though closing project stage explored in the analysis. Conclusion: The adult standardized concentration of cardiovascular intravenous infusion services is a new initiative part of the intravenous admixture program. The standardized concentration of cardiovascular will diminish healthcare professional workload and avoid economic burden on healthcare system; it is highly recommended to implement in the Kingdom of Saudi Arabia.

Keywords: Adult, Standardized, Concentration, Cardiovascular, Intravenous, Saudi Arabia.
\end{abstract}

\section{INTRODUCTION}

Medication errors are the foremost issues in the treatment process that leads to harm to hospitalized patients. ${ }^{[1-3]}$ One of the significant medication errors that can occur in the hospital settings and is utilizing numerous intravenous infusion medications. Several studies showed that errors involving intravenous infusion medications have great potential to cause serious harm to hospitalized patients. ${ }^{[4-6]}$ Standardizing concentrations of high-risk intravenous medications are being used to reduce medication errors that inevitably leading to a safer delivery system. ${ }^{[7-13]} \quad$ Cardiovascular medications characterize one of the important and highly used medications in hospitalized patients. ${ }^{[1-13]}$ There are many medication errors have been documented of cardiovascular medications, which have many different concentrations. ${ }^{[5]}$ This project purposes to prevent or at least reduce these types of medication errors by implementation and development system responsible for determining specific concentration for cardiovascular medications used in the settings of Kingdom of Saudi Arabia.

\section{METHODS}

It is a new initiative project drove by the national intravenous program. ${ }^{[14]}$ The task force team of adults standardized concentration of cardiovascular intravenous infusion medications formulated and contained of from the author's expertise in the adults parenteral medications. The committee utilized and drove the pharmacy parenteral administration guidelines and from the textbook and international literature adults standardized concentration of cardiovascular intravenous infusion medications written by utilizing the international business model, pharmacy project guidelines project management institution guidelines of a new project. ${ }^{[15-}$ 18] The adult's standardized concentration of cardiovascular intravenous infusion medications adjusted based on the acceptable concentration, daily dose and the volume of bag as possible. The project is written through project management professionals and contained of several parts, including the initial phase, the planning phase, the execution phase, the monitoring and controlling phase.

\section{Initial Phase}

\section{Assessment Needs}

Multiple hospitals have been used in numerous concentrations of cardiovascular infusion medications. Besides creating economic challenges on healthcare institutions, the use of different concentrations of cardiovascular medications may lead to medication errors that may cause adverse effects to patients and, in the long term, caused deaths. The best way of 
reducing and preventing such instances is by standardizing the prevailing concentrations.

\section{Market Analysis}

Most of the parenteral admixture services in the Kingdom of Saudi Arabia had various methods of adult cardiovascular intravenous medication concentrations. The guidelines of preparation comprised of medications, route of administration, the stability of preparation, concentration and medication compatibility. Most the healthcare organizations had the same guidelines with different medications. The adult standardized concentration of cardiovascular intravenous infusion or standardized diluent solution has not existed. The adult standardized concentration of cardiovascular intravenous infusion is an excellent method to reassure the manufacturers to produce the same readymade, standardized concentration. However, there were some ready-made medications with specific concentration a variable in the market but coveted all adult's cardiovascular medications and the concentration was not proper.

\section{SWOT Analysis}

To attain the goals of the project, a SWOT analysis was carried out. The "strengths" of the project were accompanied by the documentation of pharmacy workload for the prevention of medication errors, the estimated cost of avoidance of medication errors and the estimated cost of correction of medication errors. A limited number of resources accompanied the "weaknesses" in this project adult's standardized concentration of cardiovascular intravenous infusion medications and diluent. The opportunities that were looked into in this project encompassed the implementation of both international and local standards of healthcare organizations. It also needed how to implement the New Saudi Vision 2030 and limiting the errors that cause by using various concentration. The threats of the project included the change of pharmaceutical administration and also an analysis of the standards for accreditation.

\section{Planning Phase}

\section{Scope of the Project}

The project confined the adult's standardized concentration of cardiovascular medications with specific diluent solutions. The concentration drove from typical daily dose and frequency administration. The adults' standardized concentration of cardiovascular intravenous medications encourages pharmaceutical companies to make readymade antibiotics with resembling concentration and diluent solution.

\section{Vision, Missions and Goals}

The project's vision is to best standardization and limits the drug concentrations at healthcare institutions, particularly for drugs used in cardiovascular treatment. The mission of the project is to standardize the adult's concentrations of intravenous infusion of cardiovascular medications. The project goals included the facilitation of standardization drug concentration, preventing complications from unstandardized drug concentrations, reducing the errors, mortality, the economic challenges on the healthcare system and reduce the workload of the healthcare providers and pharmacy.

\section{Description of the Project}

The following policies were put in place for every pharmacist and other health care individuals: ${ }^{19,20}$

$\checkmark$ The increased pharmacy workload and misuse of documentation through the evaluation of the performance of the pharmacy staff committee should be formulated at healthcare institutions.

$\checkmark$ The increased pharmacy workload and misuse of documentation through the evaluation of the performance of pharmacy staff committee should consist of IV pharmacist and pharmacy technician, adults nursing representative, adult surgical or medical representative and cardiovascular clinical pharmacist.

$\checkmark$ The committee revises the adults standardized concentration of cardiovascular intravenous infusion medications annually (Table 1).

$\checkmark$ The adult's standardized concentration of cardiovascular intravenous infusion medications education and training sessions should be conducted by the committee to all healthcare providers, including physicians and nurses, with pharmacy staff.

$\checkmark$ The adults standardized concentration of cardiovascular intravenous infusion medications distributed to healthcare sectors at the institutions.

$\checkmark$ The physician writes the prescription based on the adults standardized concentration of cardiovascular intravenous infusion medications.

$\checkmark$ If the physician wishes to prescribe outside the adults standardized concentration of cardiovascular intravenous infusion medication guidelines, he should document the justification.

$\checkmark$ The prescription should send to the pharmacy and IV pharmacist and the pharmacy technician will prepare it based on the adult's standardized concentration of cardiovascular intravenous infusion medications.

$\checkmark$ The pharmacy staff sends the medications to the nursing department and the nurse administers the medications based on the adult's standardized concentration of cardiovascular intravenous infusion medication guidelines.

$\checkmark$ The pharmacy department should measure the clinical outcome of the adult's standardized concentration of cardiovascular intravenous infusion medications.

$\checkmark$ The pharmacy department should measure the economic outcome of the adult's standardized concentration of cardiovascular intravenous infusion medications.

$\checkmark$ The pharmacy department should document any prescription non-adherence to the adult's standardized concentration of cardiovascular intravenous infusion medications.

\section{Plan Cost Management}

The demand budget should be detailed in every current project of adult standardized concentration of cardiovascular intravenous infusion. The cost, including the educational courses, the management team meeting and updated references. Furthermore, the budget should be supervision for the overall period.

\section{Executing Phase \\ Management Team}

The adult standardized concentration of cardiovascular intravenous infusion project should lead by the administration team. The team entailed of adult cardiovascular clinical pharmacists, adult's intravenous admixture pharmacists, pharmacy technicians, cardiology physicians, surgeons, pharmacy total quality management and adult medications safety pharmacist. The team will implement and monitor the project. Set-up the performance indicators, policies and procedures. In addition to updating the adult standardized concentration of cardiovascular intravenous infusion list occasionally. Perform all education and training of the project for pharmacists and healthcare providers and related issues.

\section{Education and Training}

Various educational and training sessions about the adult standardized concentration of cardiovascular intravenous infusion should be conducted for pharmacy staff, including pharmacists, pharmacy technicians and healthcare providers, including physicians and nurses, should receive education and training before starting the project. Another candidate for 


$$
\mid
$$




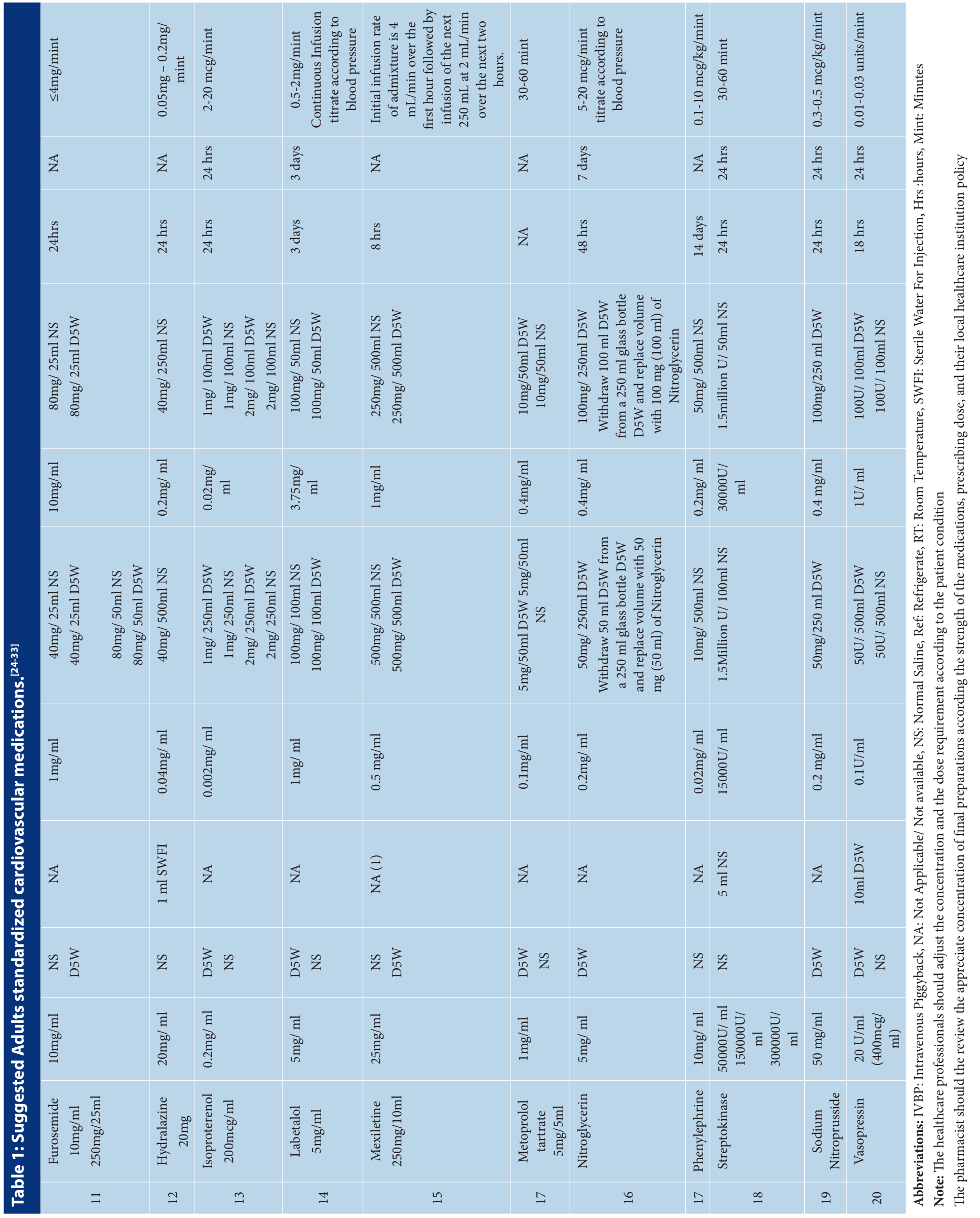


the adult standardized concentration of cardiovascular intravenous infusion education courses, the management team and proper orientation for new pharmacy or healthcare staff join the healthcare institutions.

\section{Project Total Quality Management}

There are multiple tools practice during total quantity management with new project adult's standardized concentration of cardiovascular medications during the implementation stage and reflect the outcomes. The balance scored cards was among them. ${ }^{[21]}$ The elements monitor involved of four-part including the finance, the customer, internal process, education and innovation. The assessment of healthcare and pharmacy services of adult's standardized concentration of cardiovascular medications was an example of an internal process type. The clinical impact of adult's standardized concentration of cardiovascular medications, which adequately reflect the education, competency of pharmacists and pharmacy technicians, was an example of the education type. The financial type had another example of measuring the avoidance cost of the adult's standardized concentration of cardiovascular system medications. The last type of quality management was the customer types through measures the patient's satisfaction with healthcare providers, including pharmacy staff of adults standardized concentration of cardiovascular system medications satisfaction in the Kingdom of Saudi Arabia.

\section{Risk Management}

There are several considered risks including budget risks, scope risks, schedule risks, personal risks, technical risks and quality risks. ${ }^{[22,23]}$ The project might be exposed to risks such as personnel, budget, technical and quality risks. The project suffered sufficiently from personal risks with not trained pharmacist or pharmacy technician or nor sufficient pharmacy staff. The budget risk is not just enough education and training courses to all healthcare providers' related issues. It might expose to the same. There is another of technical risk may be exposed without the electronic recourses of friendly used computer system in pharmacy practice. The project may be exposed to quality risks with nonimplemented medications safety elements or non-trained personnel.

\section{Closing of the Project}

The standardized concentration of adult's cardiovascular medications at all healthcare organizations of governmental and private sectors is required to prevent drug-related misadventures and might lead to morbidity and mortality. Moreover, to prevent additional redundant costburden on healthcare institutions, including the hospitals and primary healthcare centers services in the Kingdom of Saudi Arabia. The project should continue during the preparation of parenteral cardiovascular medications at each pharmacy unit and related committees. The standardized adult's concentration of cardiovascular medications education and training should be implemented periodically. Adult's cardiovascular medications concentration should be updated and more expand the number of medications in the future. The annual celebration of all IV admixture pharmacy staff, including the pharmacist and pharmacy technician, is highly suggested in the Kingdom of Saudi Arabia.

\section{ACKNOWLEDGEMENT}

None.

\section{CONFLICT OF INTEREST}

None.

\section{FUNDING}

None

\section{CONSENT FOR PUBLICATIONS}

Informed consent was obtained from all the participants

\section{ETHICAL APPROVAL}

This research exempted from research and ethical committee or an institutional review board (IRB) approval.

https://www.hhs.gov/ohrp/regulations-andpolicy/decision-charts-2018/index.html

\section{ABBREVIATIONS}

MOH: Ministry of Health; KSA: Kingdom of Saudi Arabia; SWOT: Strengths, Weaknesses, Opportunities and Threats; IV: Intravenous; BSC: Balance Scored Cards; IAC: intravenous admixture committee.

\section{ORCID ID}

Yousef Ahmed Alomi org/0000-0003-1381-628X

https://orcid.

\section{REFERENCES}

1. Dean B, Schachter M, Vincent CNB. Prescribing errors in hospital inpatients: Their incidence and clinical significance. Qual Saf Heal Care. 2002;11(4):340-4.

2. Al-Dhawailie AA. Inpatient prescribing errors and pharmacist intervention at a teaching hospital in Saudi Arabia. Saudi Pharm J. 2011;19(3):193-6.

3. Alsulami Z, Conroy S, Choonara I. Medication errors in the Middle East countries: A systematic review of the literature. Eur J Clin Pharmacol. 2013;69(4):995-1008.
4. Alomi1 YA, Fallatah AO, Al-Shubaar N, et al. the clinical outcomes of pharmacist interventions in total parenteral nutrition services in Riyadh City, Saudi Arabia. Int J Pharm Heal Sci. 2019;2(2):13540.

5. Alomi YA, El-Bahnasawi M, Kamran M, et al. The clinical outcomes of pharmacist interventions at critical care services of private hospital in Riyadh City, Saudi Arabia. Pharmacol Toxicol Biomed Reports. 2019;5(1):16-9.

6. Alomi YA, Alshabaar N, Lubad N, et al. Inpatient medication errors and pharmacist intervention at ministry of health public hospital, Riyadh, Saudi Arabia. Pharmacol Toxicol Biomed Reports. 2019;5(1):44-8.

7. Bullock J, Jordan D, Gawlinski A, et al. Standardizing IV infusion medication concentrations to reduce variability in medication errors. Critical Care Nursing Clinics of North America. 2006;18(4):51521.

8. Murray KL, Wright D, Laxton B, et al. Implementation of standardized pediatric i.v. medication concentrations. Am J Heal Pharm. 2014;71(17):15008.

9. Hilmas E, Sowan A, Gaffoor M, et al. Implementation and evaluation of a comprehensive system to deliver pediatric continuous infusion medications with standardized concentrations. Am J Heal Pharm. 2010;67(1):58-69.

10. Bullock J, Jordan D, Gawlinski A, et al. Standardizing IV infusion medication concentrations to reduce variability in medication errors. Crit Care Nurs Clin North Am. 2006;18(4):515-21.

11. Nemec K, Kopelent-Frank H, Greif R. Standardization of infusion solutions to reduce the risk of incompatibility. Am J Heal Pharm. 2008;65(17):1648-54.

12. Westerkamp T. Standardized concentrations for intravenous drip medications. Am J Hosp Pharm. 1988;45(9):1862

13. Lucas AT, Rowe E, Eckel SF. Determining the need for standardized infusions and concentrations at hospitals within North Carolina. Hosp Pharm. 2016;51(3):237-45.

14. Alomi YA. National Intravenous (IV) Therapy Program at $\mathrm{MOH}$ in Saudi Arabia. EC Pharm Sci. 2016;3(2-3):307-11.

15. McDonough R. Writing a business plan for a new pharmacy service. The dynamics of pharmaceutical care: Enriching patients' health. 2010;23:1-13.

16. Harris IM, Baker E, Berry TM, et al. Developing a business-practice model for pharmacy services in ambulatory settings. Pharmacotherapy. 2008;28(2):7e-34e.

17. Sachdev G. Sustainable business models: systematic approach toward successful ambulatory care pharmacy practice. Am J Heal Pharm. 2014;71(16):1366-74

18. PMBOK Guide. A guide to the project management body of knowledge. Sixth Edition. Project Management Institute Inc. 2017.

19. Mitchell A, Sommo P, Mocerine T, et al. A standardized approach to pediatric parenteral medication delivery. Hospital Pharmacy. 2004;39:433-59.

20. Sowan AK, Vaidya VU, Soeken KL, et al. Computerized orders with standardized concentrations decrease dispensing errors of continuous infusion medications for pediatrics. J Pediatr Pharmacol Ther. 2010;15(3):189-202

21. Kaplan RS, Norton DP. The balanced scorecard Measures that drive performance. Harvard Business Review. 2005;83. Cited 2020 Mar 15. Available from: https://hbr.org/1992/01/the-balancedscorecard-measures-that-drive-performance-2.

22. Ray S. The Risk Management Process in Project Management: Project Manager. 2017. Cited 2020 Mar 15. Available from: https://www.projectmanager.com/blog/risk-management-process-steps.

23. Kaplan RS, Mikes A. Managing risks: A new framework. Harvard Business Review. 2012. Cited 2020 
Mar 15. Available from: https://hbr.org/2012/06/ managing-risks-a-new-framework.

24. Ministry of Health. Ministry of Health Formulary. Health Ministry of Health. 2012.

25. Saudi Food and Drug Authority. List of human medicine and herbal health. 2019. [cited 2019 Jun 17]. Available from: https://www.sfda.gov.sa/en/ drug/resources/Pages/DrugsUnderRegistrations. aspx

26. Baxter K, Aikman K, Luckhurst R, et al. British National Formulary 78 (BNF). Royal Phamaceutical Society. 2019;1-1701
27. Alomi YA, et al. Adults Parenteral Dilution Manual. 2015. Available from: https://www.researchgate. net/publication/281710454_Adults_Parenteral_Dilution_Manual

28. Wolters Kluwer Clinical Drug Information. Inc (Lexi-Drugs). Wolters Kluwer Clinical Drug Information, Inc. 2020.

29. Drugs.com. Drugs.com, Prescription Drug Information, Interactions and Side Effects. Drugs.com. 2020. [cited 2020 Jun 16]. Available from: https:// www.drugs.com/

30. King Abdulaziz Medical City. Unified IV Manual.
2020.

31. Wolters Kluwer Clinical Drug Information. Inc. (ASHF Essentials adults and pediatrics). Wolters Kluwer Clinical Drug Information, Inc. 2020.

32. Wolters Kluwer Clinical Drug Information. Inc. (Pediatrics and Neonatal Lexi-Drugs). Wolters Kluwer Clinical Drug Information, Inc. 2020

33. Wolters Kluwer Clinical Drug Information. Inc (Nursing Lexi-Drug). Wolters Kluwer Clinical Drug Information, Inc. 2020 